\title{
Sudden and unexpected childhood deaths investigated at the Pretoria Medico-Legal Laboratory, South Africa, $2007-2011$
}

B S van Deventer, BSc, BSc Hons (Medical Criminalistics); S H Rossouw, MB ChB, MMed (Med Forens), MA;

L du Toit-Prinsloo, MB ChB, Dip For Med (SA) Path, FC For Path (SA), MMed (Path) (Forens)

Department of Forensic Medicine, School of Medicine, Faculty of Health Sciences, University of Pretoria, South Africa

Corresponding author: $L$ du Toit-Prinsloo (lorraine.dutoit@up.ac.za)

\begin{abstract}
Background. Sudden and unexpected death is well known to occur in infants, and although sudden deaths are less frequent after the first birthday, they still account for a significant proportion of childhood deaths. In $2009,1.9 \%$ of the total deaths in the USA were childhood deaths. In South Africa (SA) this proportion was much higher at 11.85\%. According to the law, sudden and unexpected deaths are generally investigated as unnatural deaths. Establishing an exact underlying anatomical cause of death will depend on available resources and can be difficult in a substantial proportion of cases.

Methods. A retrospective descriptive case audit was conducted at the Pretoria Medico-Legal Laboratory (PMLL), SA, from 1 January 2007 through to 31 December 2011. All children aged $1-18$ years who died suddenly and unexpectedly were included.

Results. Ninety-eight cases were identified, which constituted nearly $1 \%$ of total admissions to the PMLL. The majority of the deaths were of children aged 1 - 5 years, and the male/female ratio was 1.04:1. In the largest proportion of cases $(n=28,28.6 \%)$, the medicolegal investigation, including autopsy and ancillary investigations, did not establish an underlying anatomical cause of death. In the cases where a cause of death was established, pneumonia was the most common diagnosis $(n=22,22.4 \%)$.

Conclusions. The fact that the cause of the largest proportion of deaths could not be ascertained emphasises the need for consideration of additional investigative techniques, such as molecular/genetic screening, which have provided an underlying cause of death in a significant number of cases in other countries. There is a lack of published research on the causes and incidence of sudden unexpected deaths in children in SA, and further research in this area is needed.
\end{abstract}

S Afr Med J 2016;106(10):983-985. DOI:10.7196/SAMJ.2016.v106i10.11028

The sudden and unexpected death of a child is defined as the death of a child which was not anticipated as a significant possibility, 24 hours before the death, or where there was a similarly unexpected collapse leading to, or preceding the events which led to the death. ${ }^{[1]}$ Such deaths are well known to occur in the first year of life, after the neonatal period, and become less frequent after the first birthday. According to South African (SA) legislation, sudden deaths are classified as unnatural deaths in terms of the Regulations Regarding the Rendering of Forensic Pathology Service R636 and are referred for medicolegal investigation in accordance with the provisions of the Inquests Act 58 of 1959. In a significant proportion of these cases the cause will remain unascertained, so it is of the utmost importance to carry out every possible investigation. ${ }^{[2-4]}$

In 2009, $48033(1.9 \%)$ of 2437163 deaths in the USA were of children aged 0 - 18 years. ${ }^{[5]}$ In the same year in SA, 69878 children $\operatorname{died}\left(11.85 \%\right.$ of total deaths). ${ }^{[6,7]}$

The vast majority of sudden unexpected deaths of adults are due to coronary artery disease, but in children the causes are more diverse and include sudden cardiac death (SCD), central nervous system abnormalities (especially in children with epilepsy), and infectious disease (mainly in developing countries) ${ }^{[8-11]}$ SCD is reported to be the most prevalent cause of death, especially in the young (people aged $<40$ years). Structural abnormalities of the heart are detected at autopsy in most cases of SCD, but morphological abnormalities are absent in a significant proportion. ${ }^{[3,9-10,12]}$ It has been suggested that some of the latter cases may be explained by cardiac channelopathies such as long QT syndrome, Brugada syndrome and catecholaminergic polymorphic ventricular tachycardia. ${ }^{[3,9-10,12]}$
Many sudden unexpected deaths in children remain a mystery, without a possible explanation for the cause. The proportion of sudden deaths with no morphological abnormalities can range from $3 \%$ to $53 \%$. The absence of morphological findings at autopsy emphasises the importance of thorough investigations, additional examinations, and research into these deaths to obtain a better understanding of the underlying pathophysiology and to implement possible preventive measures. ${ }^{[3,9,13]}$

There is a paucity of published data on the causes and incidence of sudden unexpected deaths of children in SA. The objective of this study was to review these cases in order to document possible risk factors and trends, and identify potential strategies to prevent sudden unexpected death in children. We also envision that this study will lead to further research in this field.

\section{Methods}

A retrospective case audit was done of all sudden and unexpected deaths of children aged 1 - 18 years investigated at the Pretoria MedicoLegal Laboratory (PMLL), SA, from 1 January 2007 through to 31 December 2011. Data recorded in each case included the month of death, demographic details, autopsy findings (including ancillary investigations) and primary medical cause of death. Histological slides were reviewed by two independent pathologists. Approval was obtained from the Faculty of Health Sciences Research Ethics Committee, University of Pretoria (ref. no. 75/2013). Infants were excluded from the study. Sudden deaths in infancy are not uncommon, and in the USA 70\% of these are determined to be due to sudden infant death syndrome (SIDS). ${ }^{[14]}$ 


\section{Results}

During the 5-year study period, 11416 cases were admitted to the PMLL, 98 of which were children aged $1-18$ years who had died suddenly and unexpectedly (the study population). These sudden and unexpected deaths equate to $\sim 1 \%$ of all admissions to the PMLL.

The gender distribution was relatively equal, with a male/female ratio of 1.04:1. The majority of the deaths were of children aged 1 - 5 years $(n=50,51.0 \%)$ followed by 23 deaths in the 16 - 18-year age group (23.5\%), 15 deaths of 11 -15-year-olds (15.3\%) and 10 deaths in the 6 - 10-year age group (10.2\%). The largest number of deaths occurred in August. Some seasonal peaks were noted, typically at the change of seasons in March and November (Fig. 1).

A complete autopsy with evisceration of all organ blocks was conducted on all cases. Fig. 2 illustrates the number of ancillary investigations performed in these cases. Histological investigations were done in $73 / 98$ cases $(74.5 \%)$, toxicological investigations in 33/98 cases (33.7\%) and virological and microbiological investigations in 1 case $(1.0 \%)$ each. Review of the histological examinations showed that between 2 and 20 microscopy slides were reviewed on each case (total 493 slides, average number per case 7). The organ most often sampled was the lungs, followed by the brain and heart. In $40 / 73$ cases $(54.8 \%)$ the histological examination did not contribute to ascertaining the cause of death, in $18 / 73$ cases $(24.7 \%)$ the histological findings confirmed the macroscopic diagnosis, and in $15 / 73$ cases $(20.5 \%)$ the cause of death was determined by means of the histological examination alone. Independent review of the microscopy slides revealed no discrepancy with the diagnosis in the majority of cases (42/73, $57.5 \%$ ), minor discrepancies in $14 / 73$ cases $(19.2 \%)$ and major discrepancies in $17 / 73$ cases $(23.3 \%)$. In $28 / 98$ cases $(28.6 \%)$, no anatomical cause of death was identified after completion of the autopsy (including ancillary investigations). Pneumonia was diagnosed in 22 of the cases in which a cause of death was ascertained, 9 cases were deemed to be due to unspecified 'natural causes', and in 9 cases the investigations had not been completed pending the availability of toxicology results. Meningitis was diagnosed in 6 cases and myocarditis in 5 . The remaining 19 cases included gastroenteritis, aspiration and malignancy (Fig. 3). Analysis of the ages of the children and the causes of death revealed that 15 of the 28 deaths with unascertained causes (53.6\%) and 15 of the 22 deaths from pneumonia (68.2\%)

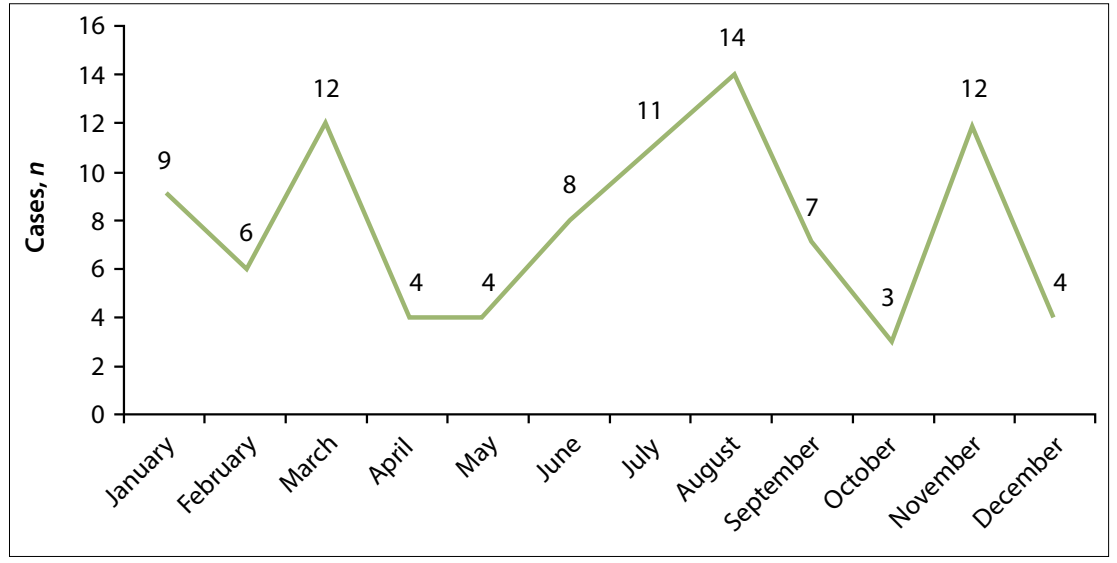

Fig. 1. Distribution of cases according to month $(\mathrm{N}=98)$.

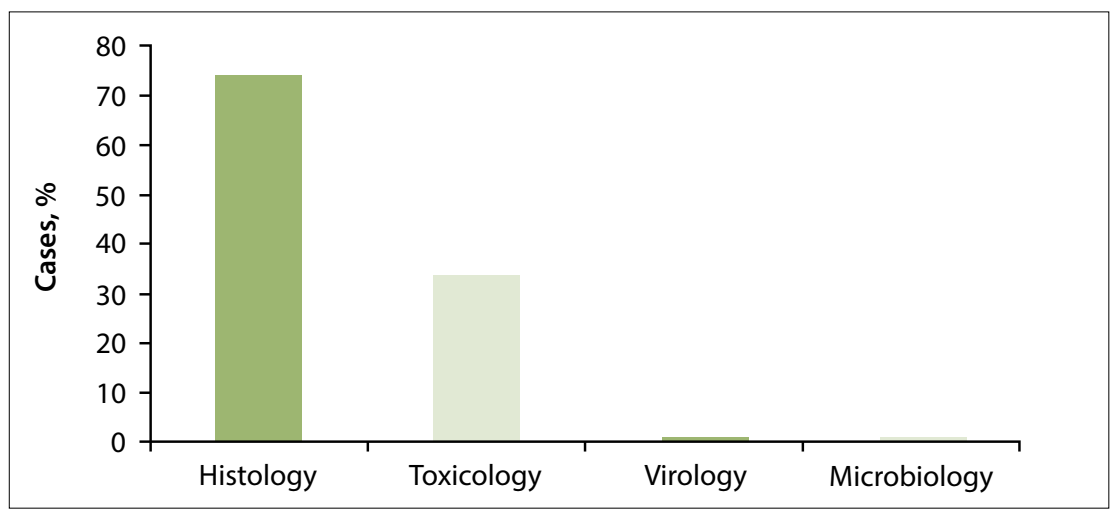

Fig. 2. Ancillary examinations performed ( $\mathrm{N}=98)$.

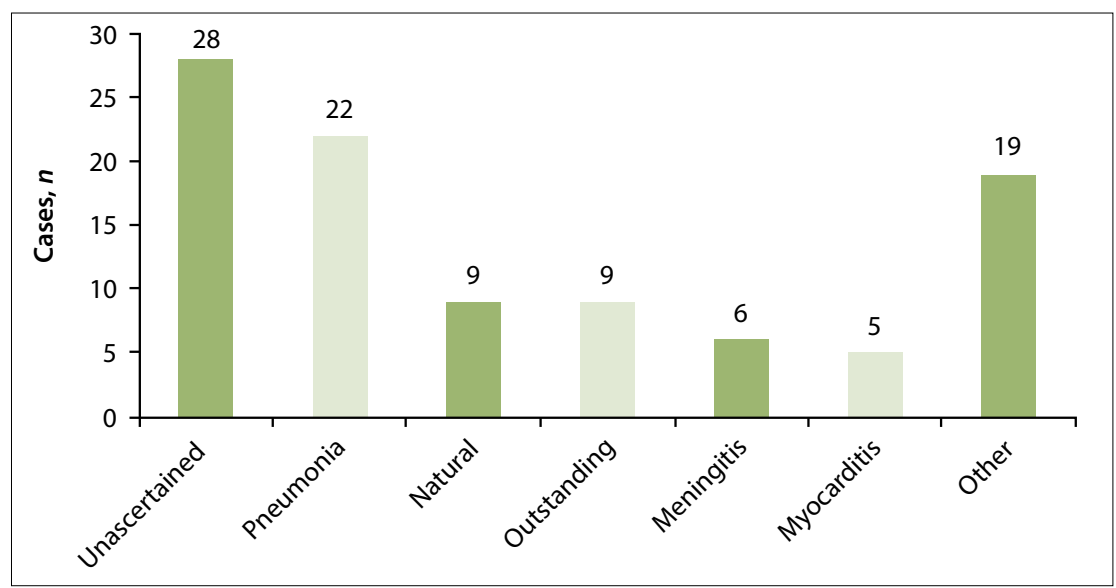

Fig. 3. Causes of death $(\mathrm{N}=98)$.

occurred in children aged between 1 and 5 years.

\section{Discussion}

Sudden and unexpected deaths in children in the USA accounted for $3 \%$ of all sudden deaths in 2009. ${ }^{[14]}$ Krous et al. ${ }^{[15]}$ reported an incidence of 1.5 deaths per 100000 live births for sudden unexplained death in childhood (SUDC) in the USA (sudden death in infants was excluded). In northern Spain (1990 1997) the reported mortality rate for sudden unexpected non-violent death in children between the ages of 1 and 19 years was 1.7 per 100000 persons per year, with $9 \%$ of all non-violent deaths in this age category being sudden and unexpected. ${ }^{[8]}$ In our study, these deaths accounted for approximately $1 \%$ of the total caseload at the PMLL.

Our results showed an equal distribution of deaths between boys and girls. Typically, the male/female ratio of cases admitted to the PMLL is 3:1. Most deaths (51.0\%) occurred in children aged 1 - 5 years. In Ireland (1994 2008), $5 \%$ of all deaths in children under the age of 5 were sudden and unexpected. ${ }^{[16]}$ 
The SUDC Foundation in the USA documented the rate of sudden unexpected childhood deaths in children aged $1-4$ years as 1.3 per 100000 children in 2014. ${ }^{[17]}$

In our study, pneumonia was determined to be the cause of death in $22.4 \%$ of the total number of cases, with the majority of these deaths occurring in children aged $1-5$ years. It can be postulated that younger children are at an increased risk of death from pneumonia. The importance of ancillary investigations in these cases, especially histological examination of tissue slides, could prove essential in making or confirming the diagnosis. The cause of death was ascertained on the basis of the histological findings alone in only $20.5 \%$ of our cases. This is lower than the $54 \%$ reported by Weber et al. ${ }^{[18]}$

Deaths for which no cause can be ascertained at autopsy (as in the largest proportion of our cases) are referred to as autopsy-negative sudden unexpected deaths (ANSUDs). As ANSUDs represent a significant proportion of total cases in our study, it would be useful to attempt to identify the underlying mechanisms that contributed to these sudden deaths. ${ }^{[3,9,13,19]}$ Advances in postmortem genetic testing (so-called 'molecular autopsy') have made it possible to identify an underlying genetic cause for some sudden unexpected deaths, indicating a cardiac-related cause of death in $35 \%$ of these deaths in children and in $10-15 \%$ of cases of SIDS..$^{[2,9]}$

\section{Conclusions}

In SA, no genetic or molecular testing is currently being done in the forensic setting owing to the high costs involved. Nevertheless, the way forward in this country is to consider a thorough molecular autopsy in each case of unexplained death to determine the cause, including cardiological and genetic evaluation of the first- and second-degree relatives of the deceased. From an ethical perspective, the question that arises is how much longer we can continue to tell family members that we do not know why their seemingly healthy beloved child died suddenly and unexpectedly. It is of utmost importance that these tests be implemented in SA in order to establish the prevalence of mutations that can result in sudden death, give answers to parents who have lost a child, and provide preventive strategies for the next of kin. Continued research in this area and studies of such cases are an absolute necessity.

1. Sidebotham P, Fleming PJ. Unexpected Death in Childhood: A Handbook for Practitioners. Chichester, UK: John Wiley \& Sons, 2007:xiii.

2. Arnestad M, Crotti L, Rognum TO, Insolia R, Pedrazzini M, Ferrandi C. Prevalence of long QT sydrome gene variants in sudden infant death syndrome. Circulation 2007;115(3):361-367. DOI:10.1161/CIRCULATIONAHA.106.65802

3. Byard RW, ed. Sudden pediatric death: An overview. In: Sudden Death in the Young. 3rd ed. New York: Cambridge University Press, 2010:1-2.

4. Côté A. Investigating sudden unexpected death in infancy and early childhood. Pediatr Respir Rev 2010;11(4):219-225. DOI:10.1016/j.prrv.2009.12.002

5. Centers for Disease Control and Prevention. National vital statistics reports. Deaths final data for 2009. http://www.cdc.gov/nchs/data/nvsr/nvsr60/nvsr60_03.pdf (accessed 10 June 2016).

6. Population Reference Bureau. 2009 world population data sheet. Updated 2014. http://www.prb.org/ Publications/Datasheets/2009/2009wpds.aspx (accessed 2 October 2013).

7. Statistics South Africa. Statistical Release P0309.3: Mortality and causes of death in South Africa, 2009: Findings 7. Statistics South Africa. Statistical Release P0309.3: Mortality and causes of death in South Africa, 2009: Finding
from death notification. www.statssa.gov.za/publications/P03093/P030932009.pdf (accessed 10 June 2016).

8. Morentin B, Aguilera B, Garamendi PM, Suarez-Mier MP. Sudden unexpected non-violent death Morentin B, Aguilera B, Garamendi PM, Suarez-Mier MP. Sudden unexpected non-violent death
between 1 and 19 years in North Spain. Arch Dis Child 2000;82(6):456-461. DOI:10.1136/adc.82.6.456 between 1 and 19 years in North Spain. Arch Dis Child 2000;82(6):456-461. DOI:10.1136/adc.82.6.456
9. Doolan A, Langlois N, Chiu C, Ingles J, Lind JM, Semsarian C. Postmortem molecular analysis . Doolan A, Langlois N, Chiu C, Ingles J, Lind JM, Semsarian C. Postmortem molecular analysis
of KCNQ1 and SCN5A genes in sudden unexplained death in young Australians. Int J Cardiol of KCNQ1 and SCN5A genes in sudden unexplained
2008;127(1):138-141. DOI:10.1016/jijcard.2007.05.001

10. Basso C, Calabrese F, Corrado D, Thiene G. Postmortem diagnosis in sudden cardiac death victims: Macroscopic, microscopic and molecular findings. Cardiovasc Res 2001;50(2):290-300. DOI:10.1016 S0008-6363(01)00261-9

11. Donner EJ. Explaining the unexplained; expecting the unexpected: Where are we with sudden unexpected death in epilepsy? Epilepsy Curr 2011;11(2):45-49. DOI:10.5698/1535-7511-11.2.45

12. Tester DJ, Spoon DB, Valdivia HH, Makielski JC, Ackerman MJ. Targeted mutational analysis of the RyR2-encoded cardiac ryanodine receptor in sudden unexplained death: A molecular autopsy of 49 medical examiner/coroner's cases. Mayo Clin Proc 2004;79(11):1380-1384. DOI:10.4065/79.11.1380

13. Tester DJ, Ackerman MJ. The molecular autopsy: Should the evaluation continue after the funeral? Pediatr Cardiol 2012;33(3):461-470. DOI:10.1007/s00246-012-0160-8

14. Chugh SS, Reinier K, Balaji S, et al. Population-based analysis of sudden death in children: The Chugh SS, Reinier K, Balaji S, et al. Population-based analysis of sudden death in children: The
Oregon Sudden Unexpected Death Study. Heart Rhythm 2009;6(11):1618-1622. DOI:10.1016/j. hrthm.2009.07.046

15. Krous HF, Chadwick AE, Crandall L, Nadeau-Manning JM. Sudden unexpected death in childhood: A Krous HF, Chadwick AE, Crandall L, Nadeau-Manning JM. Sudden unexpected death in child
report of 50 cases. Pediatr Dev Pathol 2005;8(3):307-319. DOI:10.1007/s10024-005-1155-8

16. McGarvey CM, O'Regan M, Cryan J, et al. Sudden unexplained death in childhood (1-4 years) in Ireland: An epidemiological profile and comparison with SIDS. Arch Dis Child 2012;97(8):692-697. DOI:10.1136/archdischild-2011-301393

17. The Sudden Unexplained Death in Childhood Foundation. SUDC statistics. http://sudc.org/MedicalForensic/SUDC-Statistics (accessed 10 June 2016).

18. Weber MA, Pryce JW, Ashworth MT, Malone M, Sebire NJ. Histological examination in sudden unexpected death in infancy: Evidence base for histological sampling. J Clin Pathol 2012;65(1):58-63. DOI:10.1136/jclinpath-2011-200224

19. Semsarian C, Hamilton RM. Key role of the molecular autopsy in sudden unexpected death. Heart Rhythm 2012;9(1):145-150. DOI:10.1016/j.hrthm.2011.07.034 